\title{
5 CÂMERAS QUEBRADAS: ENTRE E ALÉM DE MUROS, FRONTEIRAS E BARREIRAS.
}

\author{
Luciana Eliza dos Santos ${ }^{1}$
}

De quanta terra precisa o homem? O célebre escritor russo Liev Tolstoi (1828-1910) responde a essa pergunta com a história de um camponês, que tentou possuir tanta terra quanto seu corpo pôde alcançar, caminhando e cercando ao longo de um dia longas léguas de terra, de modo que, mediante tanto esforço, acabou restrito a sete palmos abaixo dela. 0 conto, que foi intitulado com aquele exato questionamento, evidencia uma problemática constante à história das sociedades: o desejo e a necessidade da propriedade da terra.

Apoderar-se da terra significa também pertencer à terra; neste caso, a noção de enraizamento afirma a importância das comunidades linguísticas, religiosas, culturais à integração social. Por outro lado, no que se refere aos nacionalismos e suas apropriações, a vida comum e a partilha de seus códigos são, consequentemente, construções ou imaginações sócio-históricas reguladas pela força de um estado nacional. A propriedade da terra como fronteira finita e limitada pela ideia de nação e governo representa também a "profunda camaradagem horizontal", pela qual não se busca necessariamente matar, mas pode-se frequentemente morrer (Anderson, 2008: 37).

É diante de conhecida via de conflitos pela terra que o documentário Cinco Câmeras Quebradas - Five Broken Cameras, trazido a público em 2012, abre para a recepção de diversas partes do mundo o cotidiano de ações de resistência e luta política de palestinos diante do processo de ocupação de suas terras pelo Estado de Israel, no decorrer das atuais primeiras décadas do século XXI.

O documentário de longa-metragem, que uniu olhares do palestino Emad Burnat e do israelense Guy Davidi, releva a coexitência de duas permanências contemporâneas: o belicismo como forma de (re)acomodação e disputa de fronteiras geográficas, politicas e religiosas na região que abrange o conflito árabe-israelenense, e o nebuloso conhecimento do Ocidente sobre esta realidade. Especificamente centrado na relação Palestina-Israel, o filme se passa na aldeia de Bil'in, na Cisjordânia, e aborda consequências do processo

\footnotetext{
${ }^{1}$ Possui graduação em Letras pela Universidade de São Paulo (2005), mestrado em Educação pela Universidade de São Paulo (2009) e doutorado em Educação pela mesma Universidade (2014). Tem experiência com ensino e pesquisa na área de Educação e Ensino Superior, concentrando-se principalmente nas seguintes temáticas: História, História da Educação, Anarquismo, Educação Libertária, Política Educacional. E-mail: lucianaeliz@gmail.com.
} 
de ocupação por meio de colonatos e da construção de um muro pelo estado de Israel, que toma grande parte da Cisjordânia. Esta polêmica barreira física tem cerca de $760 \mathrm{~km}$. entre Cisjordânia e Israel, abrangendo em alguns pontos 8 metros de altura. Este muro, que foi construído por Israel como uma cerca de proteção de terroristas e ataques, é antes Muro do Apartheid, atuando como uma estratégia de ocupação do território palestino.

O documentário nasceu de uma ocasião virtuosa e espontânea: em 2005, com o nascimento de seu quarto filho Gibreel, Emad Burnat inicia um processo de registro com uma câmera que não tem mais final. Burnat filma o cotidiano de sua família, os olhares de Gibreel, as ocupações de seus outros três filhos, os afazeres de sua esposa, Soraya, uma palestina que viveu no Brasil, o que aproxima a família do imaginário cultural brasileiro. Mas Burnat registra também com sua câmera o dia a dia dos conflitos pela terra, a investidas do exército de Israel na sua aldeia e a reação daquela população à imposição de um denso muro sobre suas raízes, suas práticas culturais e de sobrevivência por meio da agricultura. Por cinco anos, Burnat filma o processo de resistência e manifestação pacífica dos aldeões de Bil'in; participa de modo que a câmera testemunha e cristaliza este conflito, evidenciado suas características, desproporcionalidade e desmantelamento de comunidades palestinas por estratégias como a ocupação e o colonato, sustentados pelo Estado de Israel. São cinco câmeras necessárias a manutenção desta intervenção espontânea e mesmo instintiva por parte de Emad, ele não exercia este papel profissionalmente, mas como enfrentamento, proteção e reação. São cinco câmeras quebradas pelas reações bélicas do exército de Israel aos protestos pacíficos, aos registros e à resistência do povo palestino de Bil'in ao processo gradativo de perda de sua terra.

Como narrativa cinematográfica, o percurso de Emad Burnat, suas perdas materiais, as lesões físicas e psicológicas sofridas por ele, seus irmãos, amigos e repercutidas em sua família, expressam o importante processo de desconstrução e estranhamento da visão de Oriente associada ao terrorismo, ao exotismo e à representação europeia e americana, que homogeiniza pelo domínio histórico esta grande parte do mundo originalmente caracterizada por profundas disparidades, autenticidades e diversidades linguísticas, culturais e religiosas. 0 filme contribui para a crítica às comunidades imaginadas e dicotômicas que distinguem o mundo em Ocidente e Oriente, e acentua a desconstrução do Orientalismo como distinção ontológica e epistemológica, como discurso e lugar comum: "o Oriente é parte integrante da civilização e da cultura material europeia (2007:28)". Mas o que fica para a recepção do mundo, da crítica cinematográfica americana e europeia é que o Oriente não é um lugar tão distante; ao acompanhar a trajetória dos quatro filhos de Emad, os primeiros passos e palavras do bebê Gibreel, a maternidade de Soraya Burnat diante de uma situação de conflito e violência pela terra que lhes pertence, o documentário sensibiliza, aproxima e permite o reconhecimento do Outro.

Diante destas particularidades, há dois aspectos de 5 Câmeras Quebradas que merecem destaque: em primeiro lugar as estratégias políticas encontradas pela população 
de Bil'in para lutar por sua terra; em seguida, a sensibilidade das pessoas que vivenciam este retrato de cinco anos de duração, como as crianças, homens e mulheres que se solidarizaram e se uniram na tentativa de demonstrar a incongruência da ação bélica em uma pequena aldeia que vive de seu cultivo e cultura. Ao tornar-se uma narrativa cinematográfica, a vida deste povo torna-se um belo depoimento do enraizamento e pertencimento humano à terra, para muito além dos traçados de fronteiras e imposição do Estado e seus aparatos de poder.

Ao registrar o cotidiano de resistência de Bil'in, a câmera amadora e tremida de Emad capta todo um material humano espontâneo e poético; entre as crianças, é possível acompanhar sua gradativa inserção nos protestos aos gritos de "We want sleep! We want peace!"; o aprendizado da luta política pelo direito à vida e à terra e a dureza de ver tudo com os próprios olhos, a simplicidade de entregar um ramo de Oliveira a um soldado. As primeiras palavras de Gibreel são "jidar", muro; "matat", cartucho; "jesh", exército. Emad revela: "caminhamos ao nosso ritmo, aos passos de um bebê".

Há uma grande parceria muito bem destacada entre Emad e seus irmãos, sendo Iyad Burnat um importante líder deste movimento; e os primos Adeeb Abu-Rahma e Bassem Abu-Rahma, Adeeb e Phil, palavra árabe que significa elefante e apelidou o jovem alto e afetuoso que foi morto em uma das manifestações ocorridas em 2009. Estes parceiros estavam sempre na linha de frente dos protestos, sendo articuladores centrais, firmes e pacíficos. A partir da crescente organização desta parceria, do apoio de ativistas israelenses, dentre os quais se destaca o próprio Guy Davidi, e demais apoiadores internacionais foram organizados protestos semanais, todas as sextas-feiras, após as orações, diante do muro que atravessa as terras da aldeia e protegem a construção de habitações para colonos israelenses. Num significativo momento do filme, Adeeb abraça uma Oliveira: "nascemos nesta terra e morreremos aqui"; "viveremos nesta terra o resto de nossas vidas". À imagem destes aldeões que vivem da terra, são retratados momentos variados pela forte ligação com o lugar, com o cultivo das Oliveiras e o desejo de carregar suas heranças ancestrais e espirituais, como afirmam: "mais que alimentar, a terra liga-nos"! Adeed: Esta Oliveira que reza a Deus, o que fez com ela?", diante a remoção de uma das árvores antigas do local.

Os protestos têm faixas, bandeiras da Palestina, adultos, crianças, bordões que unificam desde a extensão da barreira às conexões inter-territoriais: "De Nil'in a Bil,in! De Nil'in a Beirute! Nós e Bil'in somos apenas um! São estratégias de ação direta nãoviolentas, pacíficas, fundadas numa relação natural, social, fisiológica e histórica com o lugar. São estratégias de pessoas comuns, populares, vinculadas pelo interesse coletivo de permanência na terra e manutenção de suas práticas religiosas, culturais e econômicas. Não são soldados, funcionários do governo, defensores de um partido, defensores da estratégia de algum partido, defensores de fronteiras ou do Estado Palestino. Estes fatores caracterizam a difusão de estratégias de luta e ação direta que representam o grande triunfo deste conflito. São protestos libertários e as formas de combate da supremacia 
estatal e da imposição autoritária dos governos se sustentam em auto-gestão, ações diretas e culturais, poéticas, que o uso da câmera oportuniza.

Em dado momento do filme, há uma cena em que um grupo de ativistas de israelenses analisam o mapa da região que abrange a extensão do muro e se dispõem a ceder as informações necessárias à organização dos protestos. A narração de Emad menciona que "gente de todo o mundo trouxe ideias criativas para o projeto". Também uma cena, na sequência desta, menciona novamente o apoio de pessoas de outras partes de mundo, neste momento ocorre uma intervenção direta no muro na qual percebe-se a presença de homens e mulheres de outras localidades e Guy Davidi.

O documentário não explicita quais são estas conexões que fortalecem os meios e criam as alternativas para a luta da população de Bil'in. 0 que se pode notar é evidenciado pelas imagens, pela presença de pessoas com aspectos e biótipos diversos, somando e registrando os protestos. Mas os agradecimentos finais do filme fazem menção a organizações que provavelmente contribuíram com o movimento e com o documentário.

Estas organizações, movimentos e associações evidenciam abrangência de uma rede que age cooperativamente, em função das regiões prejudicadas pelo Muro de Israel. Dentre elas, organizações israelenses, como a B'Tselem - The Israeli Information Center for Human Rights in the Occupied Territories, instituição criada em 1989, que atua com direitos humanos intervindo nas regiões ocupadas, em defesa dos moradores local. Esta mesma organização, em 2007, iniciou um projeto que dava acesso às câmeras para moradores palestinos das regiões de conflito, promovendo a difusão do vídeo como meio de defesa, registro e luta social, expondo a público e documentando situações de opressão e violações de direitos humanos ${ }^{2}$. Nota-se a difusão da estratégia que rendeu o filme de Emad e Guy Davidi, suposto efeito da possível interlocução e tentativa de reconhecer o uso da câmera, a documentação por imagens e o cinema como estratégias de enfrentamento, posicionamento político e ação social; uma forma de documentário interessado ou empenhado, fundado na visão dos próprios protagonistas do conflito. Emad diz: "Quando filmo sinto que a câmera me protege, mas é uma ilusão"; ele segue por cinco anos filmando.

Outro movimento presente nas entrelinhas do documentário é conhecido como Anarchists Against the Wall; uma iniciativa que surgiu em 2003 por ocasião de um acampamento de protesto na vila palestina de Mas'ha, que durou 4 meses; este movimento foi iniciativa de ativistas israelenses que passaram a promover ações e manifestações em regiões de Israel e cooperar com as populações de aldeias palestinas atingidas pela barreira. 0 movimento tem caráter internacionalista, se opõe enfaticamente à construção do Muro e defende a desobediência civil, a não-violência, a resistência palestina e a recusa israelense das estratégias de imposição e estrangulamento civil e cultural do povo palestino:

Desde o ano passado, houve um novo tipo de luta na Palestina: a luta não violenta contra o muro que o Estado de Israel está construindo no país. 0

\footnotetext{
${ }^{2}$ Informações do site da instituição: http://www.btselem.org/
} 
muro, conhecido oficialmente como "muro de separação" é na verdade uma das maiores ameaças que a população palestina tem conhecido ao longo do século passado. É uma operação "pacífica”, no sentido de que, diferentemente tantas vezes no passado, esta não é uma guerra militar total contra as pessoas, mas não deixa de ser uma guerra contra eles e contra suas terras. É uma guerra pelo controle do território, pelo controle da água, mas acima de tudo que tem um objetivo final, que é o de tornar a vida tão terrível para o povo palestino que a eles restará uma escolha: sair. Na esteira do desenfreado militarismo norte-americano do início do século XXI, o Estado de Israel está aproveitando sua oportunidade de resolver de uma vez por todas "a questão palestina". E os resultados estão à vista: a lenta propagação sobre a terra deste vergonhoso muro, o Muro do Apartheid (Federazione dei Comunisti Anarchici, $14 / 10 / 2004) \cdot{ }^{3}$

Este texto inaugura uma coletânea que trata da questão do muro e seu significado para o conflito israel-palestina e as formas de resistência para impedir o seu avanço. Tais investidas configuram um conjunto de ações relacionadas a práticas anarquistas contemporâneas, vinculando grupos e ativistas que não necessariamente ou obrigatoriamente se definem como anarquistas, mas que se utilizam de práticas de ação direta não violentas, contrárias à suplantação dos povos, seus costumes e suas terras.

As ações de correntes políticas autônomas como os Anarchists against the wall podem contribuir com a organização das populações locais na medida em que divulgam e cooperam com meios e estratégias, somando-se aos grupos, agregando força; isto é, contrárias ao apoderamento da organização espontânea destes grupos, cuja principal afinidade é a luta pela sua própria sobrevivência na sua própria terra. A associação Friends of freedom and justice Bil'in corrobora a autenticidade e autonomia do movimento entre a população de Bil'in, de modo a gerir sua permanência:

O povo de Bil'in é conhecido pela sua simplicidade, hospitalidade e boa natureza. Eles amam a paz e liberdade e lutam diariamente para rejeitar a injustiça e a opressão (...). Em linha com o seu amor pela liberdade e justiça, um grupo ativo de homens e mulheres jovens decidiu dar início a uma nova sociedade na aldeia chamada Friends of freedom and justice Bil'in. A sociedade tem como objetivo construir uma ampla rede de pessoas de todo o mundo que apoiam a liberdade e justiça para todos. 0 objectivo é reforçar a firmeza do povo palestino, para fazer difundir métodos de resistência não-violenta da comunidade e para ajudar e apoiar a educação da juventude palestina em escolas e universidades ${ }^{4}$.

0 decorrer do documentário revela situações de sofrimento, ataques diversos do exército de Israel sobre a população de Bil'in, uso da força sobre as crianças, homens e mulheres organizados de maneira manifesta em torno de ações de paz e resistência; relata o triste assassinato de Phil em uma manifestação, o que causou grande comoção e indignação; também a prisão de Emad, de um mês em cárcere e três meses em domicílio,

\footnotetext{
${ }^{3}$ We are all anarchists against the wall! On the non-violent resistance of the Israelianarchist movement and the Palestinian popular committees against the Apartheid Wall. http://www.fdca.it/fdcaen/press/pamphlets/waaaatw.htm.

${ }^{4}$ http://www.bilin-ffj.org/en/content/about-us.
} 
justificada erroneamente por ter atirado pedras contra soldados, mas motivada pela sua intervenção de registro e documentação de todos os abusos de Israel; o acidente também sofrido por Emad em uma das manifestações e que, sendo socorrido por ambulâncias de Israel, foi tratado em Tel'Aviv, mas sofreu consequências por toda a vida de lesões sérias por todo o corpo. Além das prisões de dois de seus irmãos, dentre eles Iyad Burnat, que tornou-se um representante fundamental à organização da resistência de Bil'in. Com todos estes registros visuais, sonoros e históricos de extrema violência, uso desproporcional de armas, prisões e assassinatos, o povoado de Bil'in ganhou; o documentário aponta o recuo do Estado de Israel diante do muro. Mesmo diante de tanta violência, é interessante notar como o jornal Maariv, de Israel relata este recuo:

En la primera página del Maariv, el segundo periódico más importante de Israel, había el siguiente título: "Los habitantes de Bil'in han ganado contra las FDI", con el subtítulo: "Tres años de manifestaciones violentas por los palestinos y los militantes de extrema izquierda (israelíes) que han logrado frutos: la barrera de separación cerca de Bil'in será desplazada". En el interior, en el artículo, el título es aún más elocuente: "La batalla de la barrera: el estado ha perdido en Bil'in"s.

Com a contribuição do documentário e as análises decorrentes dos eventos - as manifestações, todo o processo de organização e ao final, a vitória da população de Bil'in com o recuo do aparato militar, do muro e da travestida expropriação da terra daqueles palestinos, - nota-se a importância do processo de cooperação e ajuda mútua ocorrido entre os moradores da aldeia, ativistas israelenses e ativistas de outras regiões do mundo, configurando uma estratégia de defesa da terra que transcende limites de território, nação e governos, internacionalizando-se em virtude do enraizamento daquele povo ao seu espaço de origem, às suas tradições e ancestralidade. Por fim a mencionada associação Friends of freedom and justice Bil'in e todo o ativismo de Iyad e Emad Burnat expressam a permanência da luta palestina e a gradativa instauração de novos códigos interlocução entre fronteiras e auto-defesa. É preciso irenizar as relações de luta pela terra e pela liberdade: "Bil'in, uma aldeia pequena, tranquila, rodeada por colinas e vales, é uma aldeia palestina que está lutando para existir. Ele está lutando para salvaguardar a sua terra, suas oliveiras, seus recursos ... a sua liberdade.".

\section{Referências}

ANDERSON, Benedict. Comunidades Imaginadas - Reflexões sobre a origem e a difusão do nacionalismo. São Paulo: Cia das Letras, 2008.

\footnotetext{
${ }^{5}$ http://web.archive.org/web/20071113192159/http://www.puntodevistainternacional.org/spip. php?article32

${ }^{6} \mathrm{http}: / /$ www.bilin-ffj.org/en/content/about-us.
} 


\section{resenha de filme}

SAID, Edward W. Orientalismo - O Oriente como invenção do Ocidente, São

Paulo:Companhia de Bolso, 2007.

TOLSTOI, Liev. De quanta terra precisa o homem? São Paulo: Cia das Letrinhas, 2009.

WARSCHAWSKI, Michael. Bil'in: la victoria de David el anarquista sobre Goliat el colono. http://web.archive.org/web/20071113192159/http://www.puntodevistainternacional. org/spip.php?article32. Acesso em 20 de julho de 2016.

\section{Sitios consultados:}

http://www.ainfos.ca/07/nov/ainfos00121.html. Acesso em 20 de julho de 2016. http://www.btselem.org/ Acesso em 20 de julho de 2016.

http://www.lahaine.org/fin_de_semana_de_acciones_de_anarquistas. Acesso em 20 de julho de 2016.

http://web.archive.org/web/20071113192159/http://www.puntodevistainternacional. org/spip.php?article32. Acesso em 20 de julho de 2016.

http://www.fdca.it/fdcaen/press/pamphlets/waaaatw.htm. Acesso em 20 de julho de 2016.

http://www.bilin-ffj.org/en/content/about-us. Acesso em 20 de julho de 2016. 